Bull. Egypt. Soc. Physiol. Sci. 40 (1), 32-45

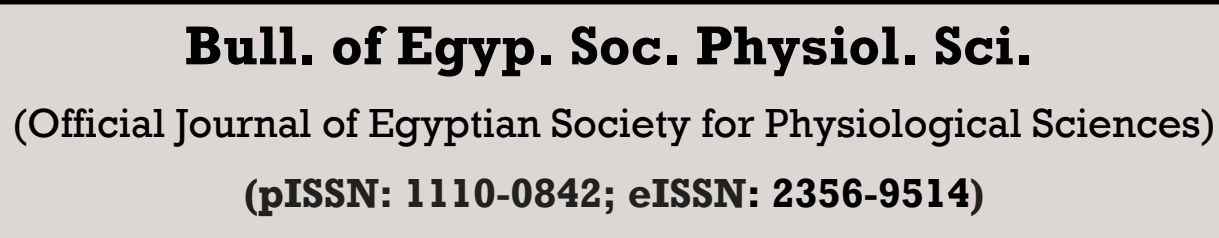

Bull. of Egyp. Soc. Physiol. Sci.

(pISSN: 1110-0842; eISSN: 2356-9514)

\title{
L-Carnitine protects kidney against ischemia reperfusion injury via suppression of expression of tubular kidney injury molecule (Kim-1) and Wnt proteins (Beta- Catenin)
}

\author{
Mohamed Adel ${ }^{1, *}$, Mohamed Rami ${ }^{1}$, Mamdouh Basheir ${ }^{2}$, Ahmed Nabawy ${ }^{2}$, Rehan Monir ${ }^{3}$, \\ Dalia Shaheen ${ }^{3}$. And Ahmed E. Eladl ${ }^{4}$ \\ ${ }^{1}$ Department of Medical Physiology, Faculty of Medicine, Mansoura University, Egypt \\ ${ }^{2}$ Department of Anatomy, Faculty of Medicine, Mansoura University, Egypt \\ ${ }^{3}$ Department of Biochemistry, Faculty of Medicine, Mansoura University, Egypt \\ ${ }^{4}$ Department of Pathology, Faculty of Medicine, Mansoura University, Egypt
}

Received: 26 June 2019 Accepted: 10 August 2019 Available online: 1 Jan 2020

\section{Keywords}

- Kim-1,

- Beta-Catenin,

- Reperfusion Injury

- L-Carnitine

\begin{abstract}
L-Carnitine is a unique nutritional supplement for athletes that has been recently studied as a potential treatment for certain renal disorders. However, its efficacy in renal ischemia reperfusion injuries has not been investigated. Rats were randomly assigned to one of five groups ( $n=6 /$ group):1, Control negative: received saline, 2,control positive I/R, rats received Sal and ischemia reperfusion at the end of fourth week and 3, L-Car $+\mathrm{I} / \mathrm{R}$ group: same as Sal and ischemia reperfusion, but rats received L-Car $(100 \mathrm{mg} / \mathrm{kg})$ intraperitoneally daily for four weeks, 4 , metformin $+\mathrm{I} / \mathrm{R}$ group: same as $\mathrm{Sal}$ and ischemia reperfusion, but rats received oral metformin (300 mg/kg/day) daily for four weeks. 5 , metformin $+\mathrm{I} / \mathrm{R}$ group $+\mathrm{L}-\mathrm{Car}$ : same as group 3, but rats received oral metformin $(300 \mathrm{mg} / \mathrm{kg} /$ day $)$ daily for four weeks. IR induced a significant increase in serum creatinine, serum $\mathrm{K}^{+}$and serum KIM-1 peaked at 24 hours after I/R. KIM-1 and $\beta$ catenin expression is upregulated 168 hours after $\mathrm{I} / \mathrm{R}$. L-Car administration led to a significant decrease in serum creatinine in proportional to $\mathrm{I} / \mathrm{R}$ group, serum $\mathrm{K}^{+}$in proportional to $\mathrm{I} / \mathrm{R}$ group, and a significant decrease in serum KIM-1 and Kim-1 expression. L-Car administration attenuated I/R-induced increase in oxidative stress marker MDA and increased antioxidant GSH activity. Moreover, the inducer of autophagy (Metformin) led to a significant decrease in serum creatinine, serum $\mathrm{K}^{+}$and a significant decrease in serum Kim-1 and Kim-1 expression in renal tissue. Overall, our results suggest a potential therapeutic role of L-Car and metformin in I/R
\end{abstract}

*Corresponding author: Mohamed Adel, Department of Medical Physiology, Faculty of Medicine, Mansoura University, Egypt. Email: made17744@yahoo.com/madel@mans.edu.eg ; Tel.: +201222218973 


\section{Introduction}

Ischemia/reperfusion injury (I/R) is characterized by restriction of blood supply to an organ followed by restoration of blood flow and re-oxygenation. The inevitable injuries may occur after infarction, sepsis and organ transplantation and this phenomena exacerbate tissue damage by initiating an inflammatory cascade including reactive oxygen species (ROS), cytokines, chemokines, and leukocytes activation ${ }^{1,2}$. In the kidney, IRI contributes to pathological conditions called acute kidney injury that is a clinical syndrome with rapid kidney dysfunction and high mortality rates ${ }^{3,4}$. The pathophysiology of $I / R$ in kidney is very complex but some pathological pathways such as activation of neutrophils, release of reactive oxygen species and other inflammatory mediators including adhesion molecules and a variety of cytokines are involved. Studies have demonstrated the beneficial effects of different agents in combat with $I / R$, for example, doxycycline through reducing the level of proinflammatory cytokines ${ }^{5,6}$, leptin by decreasing tumor necrosis factor alpha (TNF- $\alpha$ ) level and increasing nitrite level ${ }^{7}$, levosimendan through antioxidant and NO-related mechanisms ${ }^{8}$, iloprost by suppression of lipid peroxidation ${ }^{9}$ and ascorbic acid via free radical scavenging and antioxidant activities ${ }^{10,11}$.

$\mathrm{Wnt} / \beta$-catenin signaling is an evolutionarily conserved, key developmental signaling pathway implicated in organogenesis, tissue homeostasis and disease development in multicellular organisms $12,13,14,15$. Over the past several years, substantial studies have demonstrated that $\mathrm{Wnt} / \beta$ catenin signaling could have a pivotal role in promoting tubular repair and regeneration after acute kidney injuries induced by either ischemiareperfusion injury (I/R) or nephrotoxins 16, 17 However, data are also mounting that aberrant activation of $\mathrm{Wnt} / \beta$-catenin is associated with proteinuria, renal function decline and kidney fibrosis in many forms of chronic kidney diseases, regardless of whether the injury initially occurs in renal tubule-interstitium or glomeruli ${ }^{18,19,20,21,22,23}$.

In the rat model of acute kidney injury induced by I/R, Wnt 4 mRNA is reported to increase at 3 to $12 \mathrm{~h}$ while its protein level rises at 6 to $24 \mathrm{~h}$ after ischemia. This is associated with upregulation of cyclin D1 and cyclin A at 24 to $48 \mathrm{~h}$, suggesting that this signaling may be instrumental for tubular cells entering the cell cycle, a key event in tubular repair and regeneration after damage. Indeed, overexpression of Wnt4 or $\beta$-catenin promotes cell cycle progression and increases the protein expression of cyclin D1 in tubular epithelial cells in vitro, indicating that stimulation of $\mathrm{Wnt} / \beta$ catenin could be reparative in ischemic acute kidney injury. In a mouse model of ischemic acute kidney injury, renal expression of multiple Wnts including Wnt1, 2, 3, 3a, 4, 7a, 8a, 8b, 10a and 16, and $\beta$-catenin are upregulated, and the magnitude of their induction is closely associated with the severity of $\mathrm{I} / \mathrm{R}^{24}$.

$$
\text { L-Car (L-b-hydroxy-g-N-trimethyl }
$$

aminobutyric acid) is a non-protein amino acid which main sources in humans include both diet and endogenous synthesis. It is present in the free or acyl-carnitine form in the plasma ${ }^{11}$. L-Car is widely found in animal foods such as meat, fish, milk and dairy products, and it can be synthesized in liver and kidney from the amino acids lysine and methionine. Oral administration of L-Car in drinking water has potential nephroprotective 
effects against drug-induced nephropathy but its role in ischemia reperfusion is still defective ${ }^{11}$.

We set out therefore to: (i) test the hypothesis that a unilateral renal $\mathrm{I} / \mathrm{R}$ model can induce overexpression of tubular kidney injury biomarkers KIM-1 and $\beta$-catenin, if confirmed, (ii) explore the possible protective role of L-Car and inducer of autophagy metformin and their effects on oxidative stress markers, tubular kidney injury biomarker KIM-1 blood level and expression and $\beta$-catenin expression.

\section{Materials and Methods}

\subsection{Experimental Animals}

Thirty Sprague Dawley rats were used in the present study. The animals had free access to food and water and were housed in individual cages with a 12-hour light-dark cycle. The animals were adapted to these conditions for at least 1 week before being used in the experiments and general conditions were monitored throughout the study. All protocols and experimental procedures were approved by the Institutional Review Board (IRB) at Mansoura Faculty of Medicine on 20 April 2019 with Approval Code R.19.04.490-2019/04/20.

\subsection{Study Groups}

Rats were randomly assigned to one of five groups ( $n=6 /$ group):1, Control negative: received saline (Sal group), 2, control positive I/R (Sal $+\mathrm{I} / \mathrm{R}$ ), rats received $\mathrm{Sal}$ and ischemia reperfusion at the end of fourth week and 3, L-Car $+\mathrm{I} / \mathrm{R}$ group: same as Sal and ischemia reperfusion, but rats received L-carnitine hydrochloride $(100 \mathrm{mg} / \mathrm{kg}$ ) intraperitoneally daily for four weeks, I/R was done at the end of fourth week ${ }^{11}, 4$, metformin $+\mathrm{I} / \mathrm{R}$ group: same as $\mathrm{Sal}$ and ischemia reperfusion, but rats received oral metformin $(300 \mathrm{mg} / \mathrm{kg} /$ day $)$ daily for four weeks, I/R was done at the end of fourth week. 5, metformin $+\mathrm{I} / \mathrm{R}$ group $+\mathrm{L}-\mathrm{Car}$ : same as group 3, but rats received oral metformin (300 mg/kg/day daily for four weeks, I/R was done at the end of fourth week. Serum samples were obtained 24 hours, 72 hours, 120 hours and 168 hours after ischemia reperfusion surgery while renal tissue samples were obtained 168 hours after surgery only.

\subsection{I/R surgery}

After the right nephrectomy through median abdominal incision to make the solitary kidney model, the left renal artery was separated from the renal pedicle. In I/R group, the left renal artery was blocked for 45 minutes before reperfusion.

\subsection{Collection of renal samples}

After reperfusion, the animals were anesthetized with pentobarbital $[0.6 \mathrm{ml} / \mathrm{kg}]$ and the blood collected by heart puncture and allowed to clot for 30 minutes. Serum was separated by centrifugation at $2500 \mathrm{rpm}$ for 15 minutes and used for biochemical estimations. After that rats were sacrificed by cervical dislocation and the abdomen of terminated animal was cut open quickly and the kidney was immediately removed and washed thoroughly with ice-cold $0.9 \%$ sodium chloride solution [saline] and dried with filter paper and weighted. Then portion of the kidney was used to assess biochemical parameters.

\subsection{Determination of creatinine and $\mathrm{K}^{+}$in serum}

The assay is based on the reaction of creatinine with sodium picrate. Creatinine reacts with alkaline picrate forming a red complex. The time interval chosen for measurement avoids interference from other serum constituents. The intensity of the color formed is proportional to creatinine concentration in the plasma ${ }^{25}$ 
Serum samples were separated by centrifugation at $3000 \mathrm{rpm}$ for $15 \mathrm{~min}$. The clear serum was received in dry sterile tubes and used directly for determination of potassium $(\mathrm{K})^{26}$

2.6. Assay of lipid peroxidations marker malondialdhyde (MDA) and antioxidant reduced glutathione (GSH) Activity in renal tissues

About 50 -100 mg of kidney tissues will be homogenized in 1-2 $\mathrm{ml}$ cold buffer $(50 \mathrm{mM}$ potassium phosphate, $\mathrm{pH} 7.5,1 \mathrm{mM}$ EDTA) using mortar and pestle then centrifuged at 4,000 rpm for 15 minutes at $4{ }^{\circ} \mathrm{C}$. The supernatant will be kept at - $20{ }^{\circ} \mathrm{C}$ until it is used for analysis. Malondialdhyde (MDA) and reduced glutathione (GSH) in the supernatant of kidney homogenates were measured using a colorimetric method according to the manufacturer's instructions (BioDiagnostics, Dokki, Giza, Egypt).

2.7. Measurement of tubular kidney injury molecule (Kim-1) by ELISA

Tubular Kidney injury molecule (Kim-1), as a biomarker of acute kidney injury, can sensitively reflect the renal protective effect by L-Car and metformin. It was measured using Rat Kim-1 Sandwich ELISA Kit according to the manufacturer's instructions (Rat Kim-1 ELISA Kit, Boster immuneboster. Fremont, CA, USA).

\subsection{Histopathological examination of kidney} tissue by Hematoxylin and Eosin

Twenty micrometer-thick sections of kidney slices were stained with hematoxylin and eosin (H\&E), and the slides of kidney were stained with hematoxylin for 15 minutes and in $\mathrm{HCl}$ alcohol solution for 35 seconds. Then, the sections were immersed with eosin for 10 minutes and 90\% ethanol for 40 seconds. After that, the section was examined, and images of the kidney tissue were captured under light microscope.

2.9. Immunohistochemical study of a novel biomarker for the early detection of kidney tubular injury after ischemia/reperfusion injury ( $\beta$ Catenin)

Serial coronal sections $(40 \mu \mathrm{m})$ were sliced using a freezing sledge microtome, and a 1:6 series was used for all quantitative immunohistochemistry. Peroxidase-based immunostaining was completed. In brief, following quenching of endogenous peroxidase activity where appropriate (using a solution of $3 \%$ hydrogen peroxide/10\% methanol in distilled water) and blocking of nonspecific secondary antibody binding (using 3\% normal serum in Trisbuffered saline (TBS) with $0.2 \%$ Triton X-100 at room temperature for $1 \mathrm{~h}$ ), sections were incubated overnight at room temperature with the appropriate primary antibody diluted in $1 \%$ normal serum in TBS with $0.2 \%$ Triton X-100 (polyclonal anti- $\beta$ catenin rabbit antibody, Cat\#YPA1340, dilution 1:200; Chongqing Biospes Co., Ltd., Chongqing, China).

\subsection{RNA Extraction and First-strand cDNA synthesis}

For all animals, the kidney was removed for RNA extraction under standard sterile surgical method. Total RNA was extracted from kidney tissue using Trizol Reagent [Invitrogen, USA] according to the manufacturer's description and treated with RNase-free DNase to remove any residual genomic DNA. Single stranded cDNAs were synthesized by incubating total RNA [1 $[\mu \mathrm{g}]$ with Revert Aid H Minus M-MuL V Reverse transcriptase [200 U], oligo-[dT] primer $[5 \mu \mathrm{M}]$, Random Hexamer Primer [5 $\mu \mathrm{M}]$, dNTPs $[1 \mathrm{mM}]$, 
and Ribo Lock RNase-inhibitor [20 U], for 5min at $25^{\circ} \mathrm{C}$ followed by $60 \mathrm{~min}$ at $42^{\circ} \mathrm{C}$ in a final volume of $20 \mu \mathrm{l}$. The reaction was terminated by heating at $70^{\circ} \mathrm{C}$ for $5 \mathrm{~min}$.

\subsection{Real-time RT-PCR Analysis of Kim-1 Expression}

Primers for the Kim-1 gene (NM 173149, forward primer:

TGGCACTGTGACATCCTCAGA; reverse primer: GCAACGGACATGCCAACATA) and the house keeping GAPDH gene (NM 017008, forward primer: CCTGGAGAAACCTGCCAAGTAT; reverse primer: AGCCCAGGATGCCCTTTAGT) were designed using ABI Primer Express software (Applied Biosystems, Foster City, CA). Total RNA was reverse transcribed with ABI High-Capacity cDNA Reverse Transcription kit and then subjected to real-time PCR using ABI SYBR green PCR master mix (Applied Biosystems, Cheshire, UK). The cycle time values of Kim-1 were normalized with GAPDH, and the relative differences between control and $\mathrm{Cd}$ groups were calculated and expressed as percentage of controls.

\subsection{Statistical Analysis}

Values are presented as the mean (+/-) SD by using SPSS (SPSS, Sigma Plot Software, Inc, Chicago, IL) program statistical package for social science version 17 . One-way analyses of variance (ANOVA) were used to compare each molecular variable between control negative (Saline), control positive (I/R) and experimental I/R + L-Car, I/R + metformin, I/R + L-Car + metformin groups. When a significant interaction was detected, post- hoc t-tests were used to compare the two groups at different time points. Pearson correlation analyses were used to study the relationships between serum $\mathrm{K}^{+}$, serum creatinine, serum KIM-1 and KIM-1 expression in I/R group. All data were analyzed using SPSS (SPSS, Sigma Plot Software, Inc, Chicago, IL) program statistical package for social science version 17. Results were considered significant when $(\mathrm{P}<0.05)$.

\section{Results}

\subsection{The Effects of $I / R$, L-Car, metformin and (L-Car + metformin) on serum creatinine level (mg \%)}

Table (1) showed that intervention in the left kidney disturbed renal functions. The data strongly suggest renal impairment developed 24 hours after renal reperfusion. I/R led to a significant increase in serum creatinine 24 hours after renal reperfusion in proportional to control. While it decreased, significantly, in L-Car group and metformin group in proportional to $\mathrm{I} / \mathrm{R}$ group. Also, $\mathrm{I} / \mathrm{R}$ led to a significant increase in serum creatinine 72 hours after renal reperfusion, in proportional to control. While it decreased, significantly, in the L-Car group and metformin group, in proportional to $\mathrm{I} / \mathrm{R}$ group. Also, I/R led to a significant increase in serum creatinine 120 hours after renal reperfusion, significantly, in proportional to control. While it decreased, significantly, in L-Car group and metformin group, in proportional to $\mathrm{I} / \mathrm{R}$ group. Also, $\mathrm{I} / \mathrm{R}$ led to a significant increase in serum creatinine 168 hours after renal reperfusion, it increased, significantly, in proportional to control. While it decreased, significantly, in L-Car group and metformin group, in proportional to I/R group. 
Table (1): Effect of I/R, L-carnitine hydrochloride, metformin and (L-Car + metformin) on serum creatinine level (mg \%) 24 hours, 72 hours, 120 hours and 168 hours after ischemia reperfusion

\begin{tabular}{lccccc}
\hline & Control & $\begin{array}{c}\text { I/R } \\
\text { group }\end{array}$ & L-Car +I/R group & $\begin{array}{c}\text { Metformin } \\
+\mathbf{I} / \mathbf{R} \\
\text { group }\end{array}$ & $\begin{array}{c}\text { L-Car } \\
+ \text { Metformin } \\
+ \text { IR }\end{array}$ \\
\hline $\mathbf{0 ~ h .}$ & $0.59 \pm 0.08$ & $0.77 \pm 0.3^{*}$ & $0.85 \pm 0.3^{*}$ & $0.94 \pm 0.3^{*}$ & $0.75 \pm 0.4^{*}$ \\
\hline $\mathbf{2 4} \mathbf{~ h .}$ & $0.52 \pm 0.08$ & $2.32 \pm 0.1^{*}$ & $1.66 \pm 0.21^{* \#}$ & $1.72 \pm 0.1^{* \#}$ & $1.57 \pm 0.1^{*} \#$ \\
\hline $\mathbf{7 2} \mathbf{~ h .}$ & $0.73 \pm 0.07$ & $1.77 \pm 0.17^{*}$ & $0.92 \pm 0.11^{* \#}$ & $0.87 \pm 0.2^{* \#}$ & $1.43 \pm 0.1^{* \#}$ \\
\hline $\mathbf{1 2 0}$ h. & $0.55 \pm 0.07$ & $1.42 \pm 0.19^{*}$ & $0.88 \pm 0.1^{*} \#$ & $0.76 \pm 0.1^{* \#}$ & $1.44 \pm 0.1^{*}$ \\
\hline $\mathbf{1 6 8} \mathbf{~ h .}$ & $0.61 \pm 0.08$ & $1.22 \pm 0.21^{*}$ & $0.74 \pm 0.1 \#$ & $0.66 \pm 0.1 \#$ & $1.227 \pm 0.1^{*}$ \\
\hline
\end{tabular}

Test used: ANOVA followed by posthoc Tukey for multiple comparisons. Values are expressed as mean \pm S.D. $(n=6) . *(P<0.05)$ : significant in proportional to control.\# $(P<0.05)$ : significant as compared with $I / R$ group.

\subsection{The Effects of $I / R$, L-Car, metformin and}

$\left(\mathrm{L}-\mathrm{Car}+\right.$ metformin) on serum $\mathrm{K}^{+}$level (mmol/L.)

Table (2) showed that intervention in the left kidney disturbed renal functions. The data strongly suggest renal impairment developed 24 hours after renal reperfusion. I/R led to a significant increase in serum $\mathrm{K}^{+}$level, it increased, significantly, 24 hours after renal reperfusion in proportional to control. While it decreased, significantly, in the LCar group and metformin group, in proportional to $\mathrm{I} / \mathrm{R}$ group. Also, $\mathrm{I} / \mathrm{R}$ led to a significant increase in serum $\mathrm{K}^{+}$level 72 hours after renal reperfusion, it increased, significantly, in proportional to control.
While it decreased, significantly, in the L-Car group and metformin group, in proportional to $\mathrm{I} / \mathrm{R}$ group. Also, I/R led to a significant increase in serum $\mathrm{K}^{+}$level 120 hours after renal reperfusion, it increased, significantly, in proportional to control. While it decreased, significantly, in the L-Car group and metformin group, in proportional to $\mathrm{I} / \mathrm{R}$ group. Also, I/R led to a non-significant increase in serum $\mathrm{K}^{+}$level 168 hours after renal reperfusion, in proportional to control. While it decreased, significantly, in L-Car group and metformin group, respectively, in proportional to I/R group.

Table (2): Effect of I/R, L-carnitine hydrochloride, metformin and (L-Car + metformin) on serum $\mathrm{K}^{+}$level (mmol/L.) 24 hours, 72 hours, 120 hours and 168 hours after ischemia reperfusion

\begin{tabular}{lccccc}
\hline & Control & $\begin{array}{c}\text { I/R } \\
\text { group }\end{array}$ & $\begin{array}{c}\text { L-Car +I/R } \\
\text { group }\end{array}$ & $\begin{array}{c}\text { Metformin } \\
+ \text { I/R group }\end{array}$ & $\begin{array}{c}\text { L-Car } \\
+ \text { Metformin + IR }\end{array}$ \\
\hline $\mathbf{0 ~ h .}$ & $4.7 \pm 0.2$ & $4.9 \pm 0.2$ & $4.9 \pm 0.5$ & $4.5 \pm 0.9 \#$ & $4.5 \pm 0.6 \#$ \\
\hline $\mathbf{2 4} \mathbf{~ h .}$ & $4.6 \pm 0.2$ & $5.7 \pm 0.3^{*}$ & $5.1 \pm 0.2^{*} \#$ & $4.9 \pm 0.3 \#$ & $4.5 \pm 1.5 \#$ \\
\hline $\mathbf{7 2} \mathbf{~ h .}$ & $4.77 \pm 0.06$ & $5.4 \pm 0.1^{*}$ & $4.5 \pm 0.2 \#$ & $4.4 \pm 0.1 \#$ & $4.4 \pm 1.1 \#$ \\
\hline $\mathbf{1 2 0}$ h. & $4.38 \pm 0.02$ & $4.9 \pm 0.4^{*}$ & $4.5 \pm 0.2 \#$ & $4.4 \pm 0.4 \#$ & $4.9 \pm 1.3$ \\
\hline $\mathbf{1 6 8} \mathbf{h .}$ & $5.1 \pm 0.06$ & $5.4 \pm 0.2$ & $4.5 \pm 0.2 \#$ & $4.7 \pm 0.2 \#$ & $4.9 \pm 0.7 \#$ \\
\hline
\end{tabular}

Test used: ANOVA followed by posthoctukey for multiple comparisons. Values are expressed as mean \pm S.D. $(\mathrm{n}=6) . *(\mathrm{P}<0.05)$ : significant in proportional to control. \# $(\mathrm{P}<0.05)$ : significant as compared with $\mathrm{I} / \mathrm{R}$ group.

Table (3) showed that intervention in the left

3.3. The Effects of $I / R$, L-Car, metformin and (L-Car $+\mathrm{I} / \mathrm{R}+$ metformin) on serum tubular kidney injury molecule (Kim-1) kidney disturbed renal functions. The data strongly suggest renal impairment developed 24 hours after renal reperfusion. I/R led to a significant increase 
in serum Kim-1, 24 hours after renal reperfusion in proportional to control. While it decreased, significantly, in the L-Car group and metformin group, in proportional to I/R group. Also, I/R led to a significant increase in serum Kim-1 72 hours after renal reperfusion, in proportional to control. While it decreased, significantly, in the L-Car group and metformin group, in proportional to I/R group. Also, I/R led to a significant increase in

Table (3): Effect of I/R, L-carnitine hydrochloride, metformin and (L-Car + metformin) on serum Kim-1 (pg/ml.) 0 h., 24 hours, 72 hours, 120 hours and 168 hours after ischemia reperfusion

\begin{tabular}{|c|c|c|c|c|c|}
\hline & Control & $\begin{array}{c}\mathbf{I} / \mathbf{R} \\
\text { group }\end{array}$ & $\begin{array}{c}\text { L-Car }+\mathbf{I} / \mathbf{R} \\
\text { group }\end{array}$ & $\begin{array}{l}\text { Metformin }+I / R \\
\text { group }\end{array}$ & $\begin{array}{c}\text { L-Car } \\
+ \text { Metformin } \\
+ \text { IR }\end{array}$ \\
\hline $\mathbf{0}$ h. & $616 \pm 96.8$ & $633 \pm 115.7$ & $703 \pm 154.6$ & $605 \pm 93$ & $639 \pm 104$ \\
\hline 24 h. & $649 \pm 201.8$ & $3184 \pm 399 *$ & $1087 \pm 267 * \#$ & $1059 \pm 110 * \#$ & $1042 \pm 110^{* \#}$ \\
\hline $72 \mathrm{~h}$. & $641 \pm 207.8$ & $2289 \pm 325^{*}$ & $990 \pm 218 * \#$ & $890 \pm 192 * \#$ & $1039 \pm 90 * \#$ \\
\hline $120 \mathrm{~h}$. & $647 \pm 202.8$ & $2100 \pm 317 *$ & $991 \pm 210 * \#$ & $883 \pm 175^{* \#}$ & $1021 \pm 77 * \#$ \\
\hline $168 \mathrm{~h}$. & $655 \pm 201.8$ & $1783 \pm 199 *$ & $874 \pm 177 * \#$ & $877 \pm 169^{* \#}$ & $959 \pm 108 * \#$ \\
\hline
\end{tabular}

Test used: ANOVA followed by posthoctukey for multiple comparisons. Values are expressed as mean \pm S.D. $(n=6) . *(P<0.05)$ : significant in proportional to control.\# $(P<0.05)$ : significant as compared with I/R group.

3.4. The Molecular Effects of L-Car on malondialdhyde (MDA) and reduced glutathione (GSH)

Table (4) showed that $\mathrm{I} / \mathrm{R}$ led to a significant increase in renal tissue MDA concentration, 168 hours after renal reperfusion in proportional to control. While it decreased, significantly, in L-Car group, metformin group and L-Car + metformin serum Kim-1 120 hours after renal reperfusion, in proportional to control. While it decreased, significantly, in L-Car and metformin groups, in proportional to $\mathrm{I} / \mathrm{R}$ group. Also, $\mathrm{I} / \mathrm{R}$ led to a significant increase in serum Kim-1 168 hours after renal reperfusion, in proportional to control. While it decreased, significantly, in L-Car and metformin groups, in proportional to I/R group.

Table (4): Effect of I/R, L-carnitine hydrochloride, metformin and (L-Car + metformin) on malondialdhyde (MDA) (nmol/g. renal tissue) and reduced glutathione (GSH) (nmol/g. renal tissue) 168 hours after ischemia reperfusion

\begin{tabular}{|c|c|c|c|c|c|}
\hline & Control & $\begin{array}{c}\text { I/R } \\
\text { group }\end{array}$ & $\begin{array}{l}\text { L-Car }+\mathrm{I} / \mathrm{R} \\
\text { group }\end{array}$ & $\begin{array}{l}\text { Metformin }+\mathrm{I} / \mathrm{R} \\
\text { group }\end{array}$ & $\begin{array}{c}\text { L-Car } \\
+ \text { Metformin + IR }\end{array}$ \\
\hline $\begin{array}{c}\text { MDA } \\
\text { (nmol/g. renal tissue) }\end{array}$ & $10.55 \pm 0.1$ & $15.3 \pm 1.49^{*}$ & $\begin{array}{l}12.3 \pm \\
1.07 * \#\end{array}$ & $11.3 \pm 1.66 * \#$ & $12.9 \pm 3.11^{* \#}$ \\
\hline $\begin{array}{c}\text { GSH } \\
\text { (nmol/g. renal tissue) }\end{array}$ & $119.72 \pm 9.32$ & $48.76^{*}$ & $101.33^{*} \#$ & $105 \pm 27.4^{* \#}$ & $94.2 \pm 6.8^{* \#}$ \\
\hline
\end{tabular}

Test used: ANOVA followed by posthoctukey for multiple comparisons. Values are expressed as mean \pm S.D. $(\mathrm{n}=6)$. * $(\mathrm{P}<0.05)$ : significant in proportional to control. $\quad \#(\mathrm{P}<0.05)$ : significant as compared with I/R group. 


\subsection{The Effects of $I / R, L-C a r$ and metformin on} morphology of tubular cells (168 hours post I/R)

Kidney sections from I/R group (Figure 1 A) showed irregular arrangement of cells with a reduction in the number of cells, and the cells

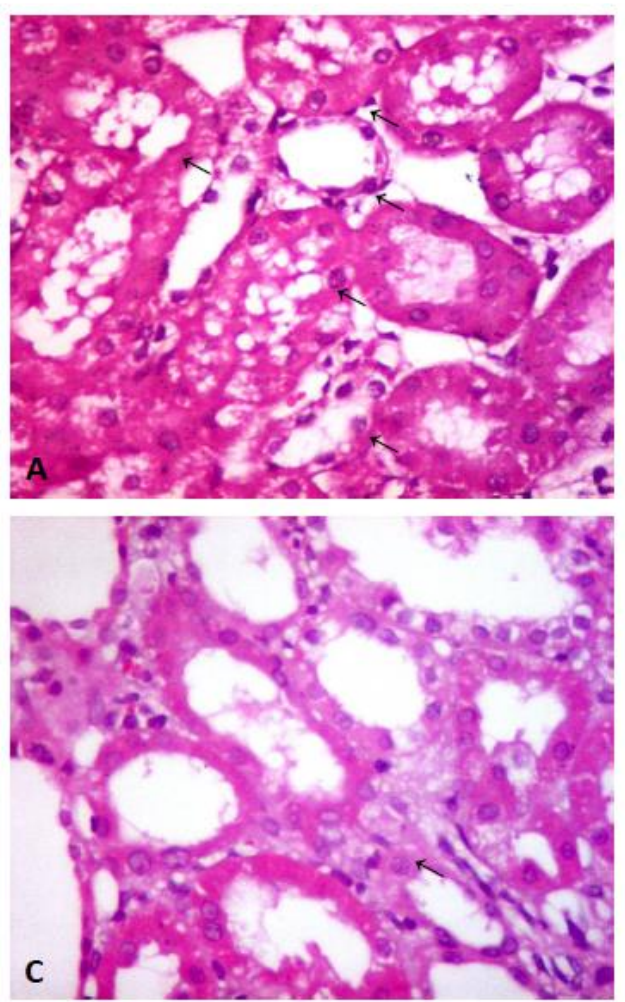

showed pyknosis (Darkly-stained nucleus and cytoplasm). The number of abnormal cells was significantly reduced in the kidney tissues obtained from (L-Car + I/R) group (Figure 1 B) and $($ Metformin $+\mathrm{I} / \mathrm{R}$ ) group (Figure $1 \mathrm{C}$ ) and (L-Car + Metformin $+\mathrm{I} / \mathrm{R}$ ) group (Figure $1 \mathrm{D}$ ).

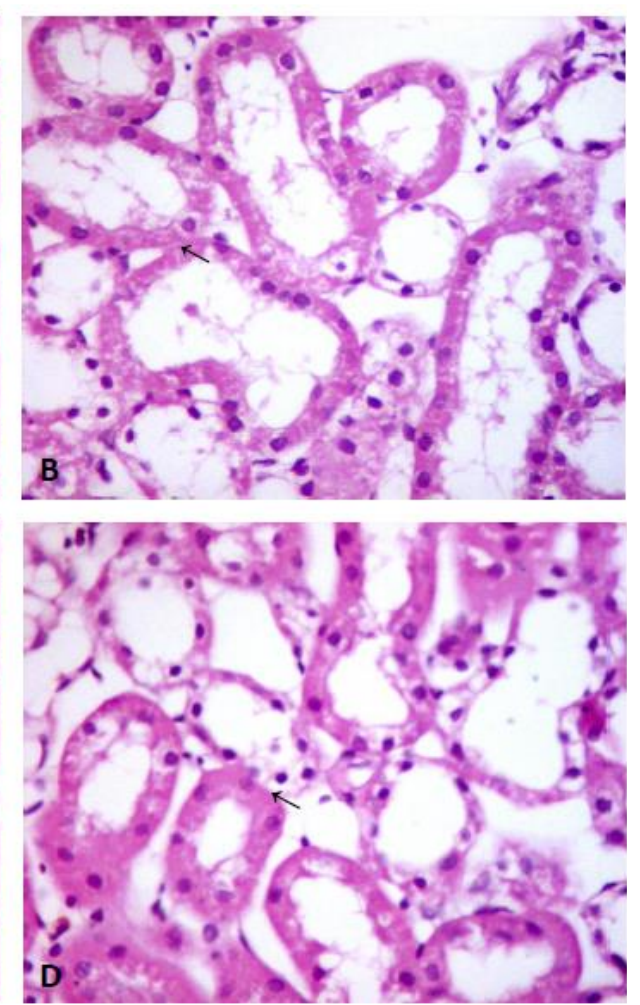

Figure (1): Histopathological examination of the renal tubules. A) H\&E staining of I/R group (n=6) (H\&E, 400 X): swollen proximal tubules epithelial lining with loss of brush border, even the tubules lumen is very narrow due to the swollen epithelial lining (arrowhead) B) H\&E staining of L-Car + I/R group (n=6) (H\&E, $400 \mathrm{X})$ : L-Car administration attenuated renal injury induced by I/R. C) H\&E staining of the metformin $+\mathrm{I} / \mathrm{R}$ group $(\mathrm{n}=6)(\mathrm{H} \& \mathrm{E}, 400 \mathrm{X})$ : metformin administration attenuated tubular injury induced by I/R. D) H\&E staining of I/R + metformin + L-Carnitine ( $n=6)(H \& E$, $400 \mathrm{X}$ ): attenuated renal injury induced by I/R.

\subsection{The Effects of $I / R, L-C a r$ and metformin on} beta-catenin expression in the renal tubules 168 hours post $\mathbf{I} / \mathbf{R}$

Kidney sections obtained from $\mathrm{I} / \mathrm{R}$ group showed enhanced expressed Wnt proteins $(\beta$ Catenin) which were localized in both injured proximal and distal renal tubules (Figure $2 \mathrm{~A}$ ). While L-Car administration led to a significant decrease in this marker expression (Figure 2 B). Also, metformin administration led to a significant decrease in its expression (Figure $2 \mathrm{C}$ ). Moreover, metformin and L-Car administration led to a significant decrease in its expression (Figure $2 \mathrm{D}$ ). 

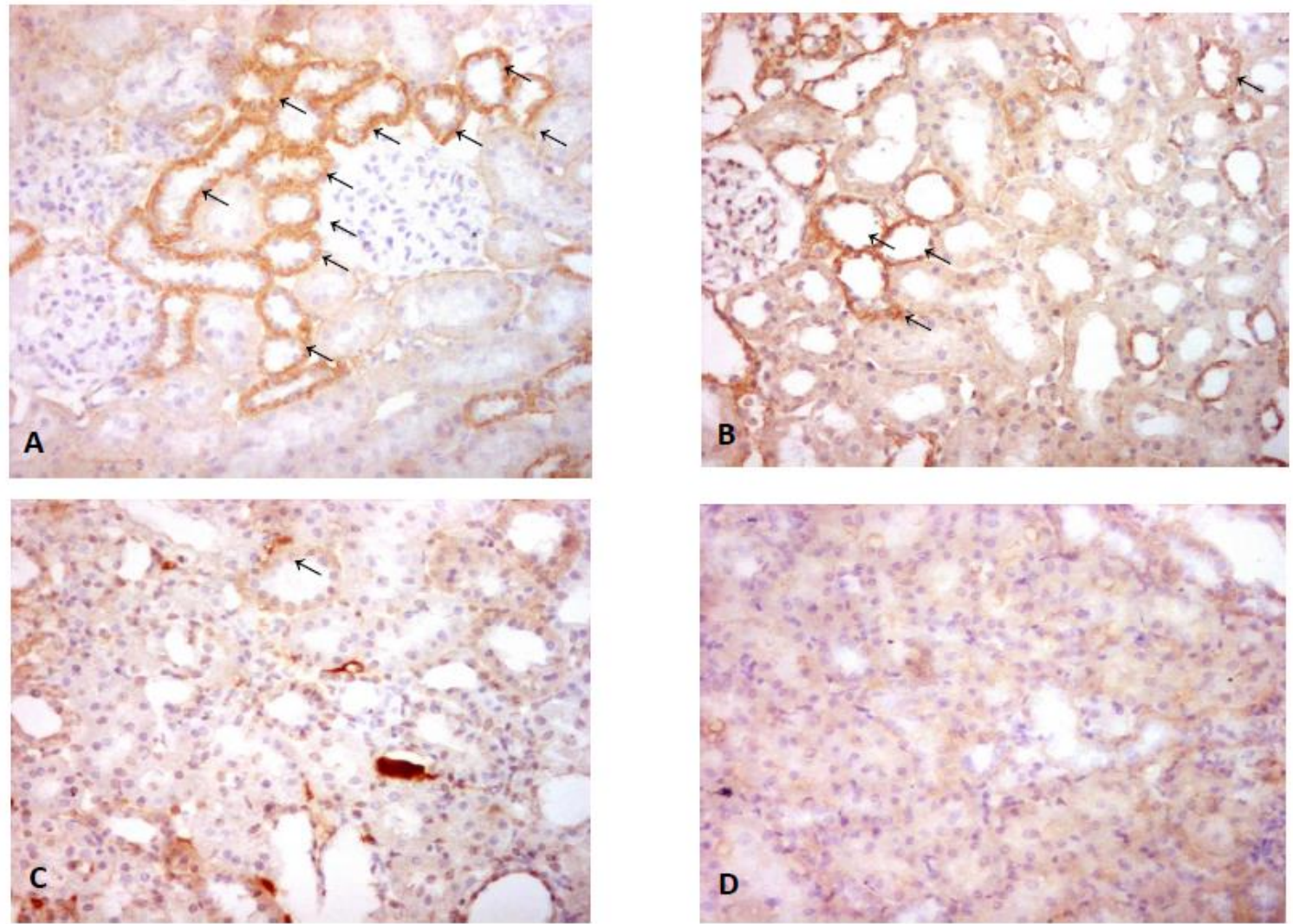

Figure (2): Enhanced expressed Wnt protein ( $\beta$ - Catenin) was localized in both the injured proximal and distal tubules following I/R Histopathological examination of renal tubules. A) Immunostaining of I/R group ( $n=6)$ : showed increased endogenous ( $\beta$ - Catenin) level, brown stain (arrowhead) (Magnification, 200X) B) L-Car administration led to a significant decrease in the biomarker of kidney injury ( $\beta$ - Catenin) (Magnification, 200X). C) Metformin administration led to a significant decrease in the biomarker of kidney injury ( $\beta$ - Catenin) (Magnification, 200X) D) Metformin and L-Car administration led to a significant decrease in the biomarker of kidney injury ( $\beta$ - Catenin) (Magnification, 200X).

\subsection{The Effects of I/R, L-Car, metformin and}

\section{(L-Car + metformin) on kidney injury molecule}

(Kim-1) expression in the renal tubules 168 hours post I/R

Figure (3) showed that kidney tubular injury molecule-1 (KIM-1) mRNA and protein expressions increased in renal tissues obtained from rats subjected to $\mathrm{I} / \mathrm{R}$ compared to Sal control rats. While L-Car treatment attenuated the increased expression of KIM-1 at the mRNA and protein levels. In addition, metformin $+\mathrm{I} / \mathrm{R}$, as well as, L-Car + metformin + I/R decreased its expression. 


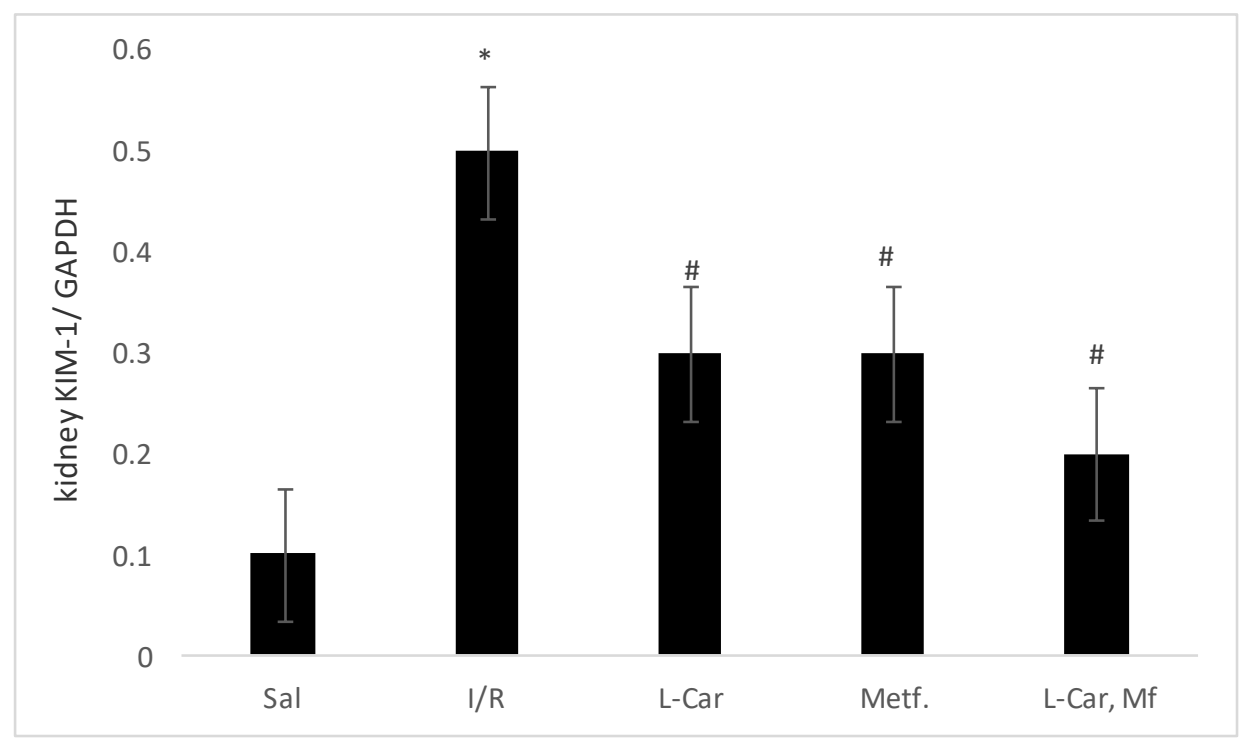

Figure (3): Products of RT-PCR for Kim-1 in Sal control group [1], I/R group [2], L-Car +I/R group [3], metformin $+\mathrm{I} / \mathrm{R}$ group [4] and L-Car +metformin $+\mathrm{I} / \mathrm{R}$ group [5] (168 hours post I/R). $*(\mathrm{P}<0.05)$ : significant as compared with Sal group. \# $(\mathrm{P}<0.05)$ : significant as compared with $\mathrm{I} / \mathrm{R}$ group.Sal: saline

3.8. Correlation between serum $\mathrm{K}^{+}$, serum creatinine, serum kidney injury molecule (Kim-

1) and KIM-1 expression in renal tubules in $I / R$
Table (5) showed that $\mathrm{I} / \mathrm{R}$ led to a significant positive correlations between serum $\mathrm{K}^{+}$, serum creatinine, serum KIM-1 and KIM-1 expression. group

Table (5): Correlations between serum $\mathrm{K}^{+}$, serum creatinine, serum KIM-1 and KIM-1 expression in I/R group

\begin{tabular}{ccccc}
\hline Parameters & Serum K & $\begin{array}{c}\text { Serum } \\
\text { Creatinine }\end{array}$ & $\begin{array}{c}\text { Serum } \\
\text { KIM-1 }\end{array}$ & $\begin{array}{c}\text { KIM-1 } \\
\text { expression }\end{array}$ \\
\hline Serum K ${ }^{+}$ & $\mathrm{r}$ & 0.910 & 0.830 & 0.801 \\
& $\mathrm{p}$ & 0.000 & 0.000 & 0.000 \\
\hline Serum & $\mathrm{r}$ & & 0.514 & 0.464 \\
Creatinine & $\mathrm{p}$ & & 0.010 & 0.022 \\
\hline Serum & $\mathrm{r}$ & & & 0.860 \\
KIM-1 & $\mathrm{p}$ & & & 0.000 \\
\hline
\end{tabular}

Kim-1: Kidney injury molecule. $\mathrm{r}$ : Pearson's correlation coefficient $\mathrm{p}$ : Probability. $\mathrm{P}<0.05$ : is considered significant. $\mathrm{P}<0.001$ : is considered highly significant.

\section{Discussion}

The main findings in the present study are: (a) $\mathrm{I} / \mathrm{R}$ increased serum creatinine and serum $\mathrm{K}^{+}$ and serum KIM-1 significantly in proportional to control, which peaked at 24 hours post ischemia/reperfusion injury (I/R) (b) $\beta$-catenin and KIM-1 expressions were upregulated in the injured renal tubules post ischemia/reperfusion injury (I/R) (c) L-Car administration led to a significant decrease in serum creatinine, serum $\mathrm{K}^{+}$and serum Kim-1, $\beta$-catenin and Kim-1 expression in proportional to $I / R$ (d) the inducer of autophagy (Metformin) led to a significant decrease in serum creatinine, serum $\mathrm{K}^{+}$and serum Kim-1, Kim-1 expression and $\beta$-catenin expression in proportional to $\mathrm{I} / \mathrm{R}$ 
Following I/R, the kidney often recovers its structure and function via adaptive repair and regeneration. This process can be considered as an innate wound-healing response consisting of the injury, repair and recovery phases. Both gain- and loss-of-function studies indicate that $\mathrm{Wnt} / \beta$ catenin plays an essential role in minimizing initial kidney damages and promoting adaptive repair and regeneration after acute kidney injuries 27, 28, 29. Kidney injury repair following acute kidney injuries involves several distinct biologic events including tubular damage/cell death, tubular cell proliferation, followed by resolution of renal fibroblasts and inflammation, and restoration of microvasculature. It appears that $\mathrm{Wnt} / \beta$-catenin signaling participates in the most majority of these reparative events, leading to accelerated regeneration and recovery. In the present study, I/R increased serum creatinine and serum $\mathrm{K}^{+}$level, significantly in proportional to control, which peaked at 24 hours post ischemia/reperfusion injury (I/R). Also, KIM-1 and beta-catenin expression is upregulated in the injured renal tissue 168 hours after I/R. The deteriorated kidney functions could be explained by initiation of an inflammatory cascade including reactive oxygen species (ROS), cytokines, chemokines, and leukocytes activation. During IRI, the damaged tissue produce excessive amount of ROS cause oxidative stress which changes mitochondrial oxidative phosphorylation, ATP depletion, increase intracellular calcium and activation of membrane phospholipids proteases. The blood flow during reperfusion phase of IRI can produce oxygen free radicals which leads to lipid peroxidation as main pathway of free radical tissue injuries. Formation of free radicals develops renal tissue injury via peroxidation of membrane lipids and oxidative damage of proteins and DNA contribute to apoptosis and cell death. Also the down regulation of the antioxidant enzyme system such as catalase, superoxide dismutase, and glutathione peroxidase could be responsible for the pathophysiology of ischemia-reperfusion injury. Therefore inhibiting this pathway or prevention of free radical production is the strategy to protect the tissue during IRI.

In the present study, L-Car administration for four weeks led to a significant decrease in serum creatinine, serum $\mathrm{K}^{+}$, and a highly significant decrease in serum KIM-1, beta-catenin and Kim-1 expression in renal tissue. In addition, L-Car administration for four weeks attenuated I/Rinduced increase in the level of oxidative stress marker malondialdehyde (MDA) and increased antioxidant GSH activity. Moreover, the inducer of autophagy (Metformin) administration for four weeks led to a significant decrease in serum creatinine, serum $\mathrm{K}^{+}$and a highly significant decrease in serum Kim-1, beta-catenin and Kim-1 expression in renal tissue. Overall, our results suggest a potential therapeutic role of L-Car and metformin in $\mathrm{I} / \mathrm{R}$

The role of autophagy in acute kidney injury remains controversial. Although we and others provided evidence for a renoprotective role of autophagy in acute kidney injury ${ }^{30,31,32,33}$. In the present study, the inducer of autophagy (Metformin) led to a significant decrease in serum creatinine, serum $\mathrm{K}^{+}$and serum Kim-1. In kidneys, autophagy is essential to the homeostasis and physiological function of podocytes ${ }^{34}$. Notably, autophagy induction has been demonstrated in 
renal tubular cells in experimental models of acute kidney injury induced by ischemia-reperfusion and nephrotoxicants ${ }^{35,36}$. Post-ischemic acute kidney injury is the most important cause of acute kidney injury, and proximal tubular cells are the main lesion of this injury ${ }^{37}$. The proximal tubulespecific autophagy-deficient mice exhibited more severe injury than control mice, with rapid accumulation of p62- and ubiquitin-positive inclusion bodies in response to I/R injury, showing that autophagy plays a protective role against $I / R$ injury ${ }^{37}$.

\section{Conclusions}

The results of the present study confirmed the renoprotective action of L-Car and metformin against I/R injury. This effect might be explained on the basis of detected L-Car and metformin actions such as antioxidant activity, anti-apoptotic effects, suppression of $\mathrm{I} / \mathrm{R}$-induced increase in the blood level and renal tissue expression of kidney injury biomarkers tubular kidney injury molecule (Kim-1) and Wnt proteins (Beta- Catenin). However, further knockout experiments will be required to study the detailed molecular mechanism of L-Car. Overall, our results suggest a potential nephroprotective effect of L-Car and metformin in I/R.

\section{Acknowledgement}

Mansoura experimental research center (MERC) is acknowledged for its contribution to the experimental part of the study.

Author Contributions: Mohamed Adel: shared in the idea, the induction of I/R model, biochemical analysis, data analysis and paper writing.
Mohamed Ramy: shared in the induction of $\mathrm{I} / \mathrm{R}$ model and paper writing. Dalia Shaheen: RTPCR, biochemical analysis and paper writing Rehan M.: RT- PCR, biochemical analysis and paper writing. A. Nabawy: the induction of $I / R$ model and sample collections. Mamdouh Basheir: the induction of $\mathrm{I} / \mathrm{R}$ model and sample collections. Ahmed E. Eladl: histopathological examination and sample collections

Conflicts of Interest: The authors declare no conflict of interest

\section{References}

1. Jang HR, Rabb H. The innate immune response in ischemic acute kidney injury. Clin Immunol. 2009;130:41-50.

2. Sharfuddin AA, Molitoris BA. Pathophysiology of ischemic acute kidney injury. Nat Rev Nephrol. 2011;7:189-200.

3. Kellum JA, Unruh ML, Murugan R. Acute kidney injury. Clin Evid 2011b. 2011

4. Hoste EA, Clermont G, Kersten A, Venkataraman R, Angus DC, De Bacquer D. et al. RIFLE criteria for acute kidney injury are associated with hospital mortality in critically ill patients: a cohort analysis. Crit Care. 2006;10:R73.

5. Kucuk A, Kabadere S, Tosun M, Koken T, Kinaci M, Isikli B. et al. Protective effects of doxycycline in ischemia/reperfusion injury on kidney. J Physiol Biochem. 2009;65:183-91.

6. İhtiyar E, Yaşar NF, Erkasap N, Köken T, Tosun M, Öner S. et al. Effects of doxycycline on renal ischemia reperfusion injury induced by abdominal compartment syndrome. J Surg Res. 2011;167:113-20. 
7. Erkasap S, Erkasap N, Koken T, Kahraman

A, Uzuner K, Yazihan N. et al. Effect of leptin on renal ischemia-reperfusion damage in rats. $\mathrm{J}$ Physiol Biochem. 2004;60:79-84.

\section{Grossini E, Molinari C, Pollesello P, Bellomo}

G, Valente G, Mary D. et al. Levosimendan protection against kidney ischemia/reperfusion injuries in anesthetized pigs. J Pharmacol Exp Ther. 2012;342:376-88.

\section{Döslüoğlu HH, Aktan AÖ, Yeğen C, Okboy}

N, Yalçm AS, Yahn R. et al. The cytoprotective effects of verapamil and iloprost (ZK 36374) on ischemia/reperfusion injury of kidneys. Transpl Int. 1993;6:138-42.

10. Korkmaz A, Kolankaya D. The protective effects of ascorbic acid against renal ischemiareperfusion injury in male rats. Ren Fail. 2009;31:36-43.

\section{Jafari A. Dashti-Khavidaki S, Khalili H,}

Lessan-Pezeshki M. Potential nephroprotective effects of 1-carnitine against drug-induced nephropathy: a review of literature. 2013 Jul;12(4):523-43..

12. Peifer $\mathbf{M}$, Polakis $\mathbf{P}$. Wnt signaling in oncogenesis and embryogenesis--a look outside the nucleus. Science. 2000; 287:1606-1609. 12

13. Lancaster MA, Louie CM, Silhavy JL, et al. Impaired Wnt-beta-catenin signaling disrupts adult renal homeostasis and leads to cystic kidney ciliopathy. Nat Med. 2009; 15:1046-1054. 13

14. Angers S, Moon RT. Proximal events in Wnt signal transduction. Nat Rev Mol Cell Biol. 2009; 10:468-477.

15. Clevers H, Nusse R. Wnt $/ \beta$-catenin signaling and disease. Cell. 2012; 149:1192-1205.

16. Zhou D, Li Y, Lin L, et al. Tubule-specific ablation of endogenous beta-catenin aggravates acute kidney injury in mice. Kidney Int. 2012; $82: 537-547$

17. Lin SL, Li B, Rao S, et al. Macrophage Wnt7b is critical for kidney repair and regeneration. Proc Natl Acad Sci USA. 2010; 107:4194-4199.

18. He W, Dai C, Li Y, et al. Wnt/beta-catenin signaling promotes renal interstitial fibrosis. J Am Soc Nephrol. 2009; 20:765-776.

19. Dai C, Stolz DB, Kiss LP, et al. Wnt/betacatenin signaling promotes podocyte dysfunction and albuminuria. J Am Soc Nephrol. 2009; 20:1997-2008

20. Surendran K, Schiavi S, Hruska KA. Wntdependent beta-catenin signaling is activated after unilateral ureteral obstruction, and recombinant secreted frizzled-related protein 4 alters the progression of renal fibrosis. J Am Soc Nephrol. $2005 ; 16: 2373-2384$

21. He W, Kang YS, Dai C, et al. Blockade of Wnt/ $\beta$-catenin signaling by paricalcitol ameliorates proteinuria and kidney injury. J Am Soc Nephrol. 2011; 22:90-103.

22. Hao S, He W, Li Y, et al. Targeted inhibition of $\beta$-catenin/CBP signaling ameliorates renal interstitial fibrosis. J Am Soc Nephrol. 2011; 22:1642-1653.

23. DiRocco DP, Kobayashi A, Taketo MM, et al. Wnt4/beta-catenin signaling in medullary kidney myofibroblasts. J Am Soc Nephrol. 2013; 24:1399-1412.

24. Xiao L, Zhou D, Tan RJ, et al. Sustained activation of $\mathrm{Wnt} / \beta$-catenin signaling drives AKI to CKD progression. J Am Soc Nephrol. 2015 In revision. 
25. Murray RL. Clin chem. St Louis, Toronto, Princeton: The C.V. Mosby Co.; 1984. pp. 1261-1266; 418

26. Berry MN, Mazzachi RD, Rajakovic M. Enzymatic determination of potassium in serum. Clin Chem 1989; 35:817-820.

27. Zhou D, Li Y, Lin L, et al. Tubule-specific ablation of endogenous beta-catenin aggravates acute kidney injury in mice. Kidney Int. 2012; 82:537-547. [PubMed: 22622501]

28. Lin SL, Li B, Rao S, et al. Macrophage Wnt7b is critical for kidney repair and regeneration. Proc Natl Acad Sci USA. 2010; 107:4194-4199.

29. Kuncewitch M, Yang WL, Corbo L, et al. WNT Agonist Decreases Tissue Damage and Improves Renal Function After IschemiaReperfusion. Shock. 2015; 43:268-275.

30. Jiang M, Liu K, Luo J et al. Autophagy is a renoprotective mechanism during in vitro hypoxia and in vivo ischemia-reperfusion injury. Am J Pathol 2010; 176: 1181-1192.

31. Pallet N, Bouvier N, Legendre $C$ et al. Autophagy protects renal tubular cells against cyclosporine toxicity. Autophagy 2008; 4: 783791.

32. Periyasamy-Thandavan S, Jiang $M$, Wei $Q$ et al. Autophagy is cytoprotective during cisplatin injury of renal proximal tubular cells. Kidney Int 2008; 74: 631-640.

33. Yang C, Kaushal V, Shah SV et al. Autophagy is associated with apoptosis in cisplatin injury to renal tubular epithelial cells. Am J Physiol Renal Physiol 2008; 294: F777-F787.

\section{Hartleben B, Godel M, Meyer-Schwesinger}

C et al. Autophagy influences glomerular disease susceptibility and maintains podocyte homeostasis in aging mice. J Clin Invest 2010; 120: 10841096.

35. Chien CT, Shyue SK, Lai MK. Bcl-xL augmentation potentially reduces ischemia/reperfusion induced proximal and distal tubular apoptosis and autophagy. Transplantation 2007; 84: 1183-1190.

36. Bolisetty S, Traylor AM, Kim J et al. Heme oxygenase-1 inhibits renal tubular macroautophagy in acute kidney injury. J Am Soc Nephrol 2011; 21: 1702-1712.

37. Lameire N, Van Biesen W, Vanholder R: Acute renal failure. Lancet 365: 417-430, 2005 